\title{
ENTORNO SANITARIO Y CAUSA DE LA MUERTE EN EL TERMINO PARROQUIAL DE SANTA MARIA, DURANTE EL SIGLO XIX
}

\author{
Miguel ANGEL ESTEVE GONZÁLEZ
}

En el presente trabajo vamos a señalar la causa de los óbitos en el término parroquial de la Iglesia de Santa María, en el período comprendido entre los años 1840 y 1900 . Esta zona abarca los barrios de Villavieja y Arrabal Roig, así como una pequeña parte de los de San Roque y el Carmen. La fuente principal de este estudio la constituyen las partidas parroquiales de defunciones, en las que figura la causa de la muerte a partir de 1838. También consideramos de utilidad exponer las condiciones higiénicas y sanitarias, así como la configuración urbana de Alicante y sus barrios, tal como las veían los hombres del siglo pasado. Para este punto hemos encontrado una interesante bibliografía.

A modo de orientación podemos decir que la población que habitaba en Villavieja y Arrabal Roig, según los censos del Archivo Municipal, era de 2.000 habitantes en 1803, 2.296 en 1850, y 2.963 en el año 1900. La población que habitaba en el término parroquial de Santa María era algo superior, ya que comprendia, como dijimos anteriormente, pequeñas zonas de otros barrios colindantes. Desgraciadamente no existen censos parroquiales completos. En cuanto a la ciudad de Alicante sabemos que en 1803 tenía 17.672 habitantes, en 1850 la suma ascendía a 19.650, y en 1900 la cifra era de 50.142 personas.

Estos datos numéricos nos ayudarán a comprender algunas cifras absolutas de defunciones y la importancia relativa de los barrios estudiados, en el marco de la totalidad del término municipal. 
A continuación vamos a analizar los barrios en que se dividía la ciudad, haciendo especial hincapié en la Villavieja y el Arrabal Roig. La documentación relativa a los siglos XVIII y comienzos del XIX divide el casco urbano en cinco barrios: Ciudad, Villavieja, Arrabal de San Antón, Arrabal de San Francisco y Arrabal Roig.

En 1803 el número de casas para toda la ciudad era de 3.056, de las cuales los barrios de Villavieja y Arrabal Roig tenían 387. ${ }^{1}$ Los censos municipales que comienzan en 1841 , dividen al término alicantino en catorce cuarteles. Los que hacen el número 12 y 13 más una pequeña porción del 11 abarcan nuestros dos barrios.

En febrero de 1859 una Real orden autoriza el derribo de las murallas, sintoma evidente de que la ciudad crecía. ${ }^{2}$

A partir de 1889 la división municipal pasa de cuarteles a distritos, y en 1897 la división a efectos censales es en secciones. Pero independientemente de las clasificaciones territoriales que se realizaban para la elaboración de los padrones de población, existían barrios perfectamente configurados.

Manero distingue los siguientes: "En primer lugar, el centro, que está dedicado al comercio. Además de éste resta mencionar los barrios que, a manera de semicírculo, rodean la capital en la curva de oeste a sureste por la parte norte. El Arrabal de San Francisco y Barrio Nuevo, formado con casas en su mayor parte de reciente construcción. El barrio de San Antón es el más extenso y le adornan tan buenas casas y calles como los anteriores, excepto en su punto más alto que tiene algunas pendientes - a continuación añade - y los barrios, Santa Cruz, San Roque, Carmen y Villavieja, que ocupan la falda del monte de Santa Bárbara son de más pobre apariencia, con calles estrechas y escalonadas, y casas reducidas, y, por último, el Arrabal Roig, aunque ocupa un punto llano, aparece con el mismo aspecto de los últimos y sirve de morada a los pescadores." ${ }^{3}$

1 A(rchivo) M(unicipal) de A(licante): Arm. 5, s. n.

2 A. M. A. Libro de Actas 151.

3 Manero, E.: "Estudios sobre la Topografía médica de Alicante», pág. 56. 
Desde el punto de vista higiénico los puntos negros de la ciudad eran los barrios, del Carmen, Santa Cruz, San Roque, Villavieja y Arrabal Roig.

En 1886 otro escritor alicantino insistía en este problema y afirmaba: "Si los alcaldes y las Juntas Locales de Sanidad cumpliesen rigurosamente con su deber..., si girasen periódicas visitas al barrio de San Antón... y a los barrios de Santa Cruz y Villavieja... es seguro que hubiesen adoptado oportunas disposiciones que hicieran habitables aquellos albergues... Hacinados en el breve espacio de algunos metros de terreno subdividido en varios cuartos, viven con escándalo de la moral, diversas familias, hombres, mujeres y animales, sin aire suficiente para respirar, $y$ en una atmósfera envenenada por el aliento, envenenada por el olor nauseabundo de las bestias, envenenada por la luz artificial $y$ el fuego de las hornillas, y envenenada por fin, por las repugnantes emanaciones de las aguas fecales, que, a falta absoluta de alcantarillas, arrojan los moradores de esos albergues, a las inmediaciones del barrio.. ${ }^{4}$

No debieron cambiar mucho las cosas para los llamados "barrios altos del interior" puesto que, en 1894, los autores de la llamada "Memoria Higiénica de Alicante" exponen que los barrios de Santa Cruz, del Carmen, San Roque y Arrabal Roig, que reunidos forman la primitiva ciudad de Alicante, no son susceptibles de mejoras, a excepción del último. Además apuntan las siguientes palabras:

Admira que pueda existir la vida en aquella zona, en la que sólo por escalinatas puede verificarse el tránsito de una a otra calle y aún para penetrar en las viviendas; en que las aguas de la torrencial lluvia inunda las habitaciones $-y-$ en que la amenaza de derrumbamiento de peñascos es constante... Verdad es que alli, como en la parte alta del barrio de San Antón, mora como en hacinado haz la clase jornalera, la que menos recursos cuenta, la que menos alquileres puede pagar, y por tanto, la que más privaciones sufre. $^{5}$

4 Carreras, P.: "Medios de mejorar las condiciones higiénicas de Alicante", págs. 14 y 15.

5 Sánchez Santana, E.-Guardiola Picó, J.: "Memoria Higiénica de Alicante", pág. 47. 
En cuanto al número de edificios con que contaba Alicante sabemos que, en 1883, ascendían a 3.914 en la ciudad propiamente dicha, mientras que las partidas rurales reunian, por su parte, 1.752 casas. En 1894 la ciudad tenía 4.289 edificios, distribuidos en los siguientes grupos: 1.507 viviendas de un solo piso, 1.287 de dos y 1.495 de tres o más. Las viviendas de un solo piso están esparcidas en los barrios de Villavieja, Santa Cruz, San Roque, el Carmen, parte de San Antón, Arrabal Roig y el Molino. Re-, firiéndose a estos edificios los autores de là «Memoria Higiénica" afirman que: "Las habitaciones son reducidísimas, la ventilación imposible y la viabilidad pésima. La planta de los edificios no alcanza más de 20 metros superficiales, carecen de patios... No hay alcantarillado, así es que los retretes no son más que pequeños pozos abiertos ẹn la peña... No tienen esas casas más_que un solo hueco: la puerta de entrada por donde únicamente puede penetrar la luz y el aire, y allí viven las familias, hacinadas, mezcladas con los animales domésticos.. ${ }^{6}$

Para el resto de la ciudad, el Arrabal de San Francisco era el que menos condiciones higiénicas poseía. Sus casas estaban a poca altura sobre el nivel del mar, y aunque constaban de dos pisos, tenían la planta baja enterrada a modo de sótano como consecuencia del establecimiento de rasantes y aceras. Reunían por esto dichas viviendas "las más pésimas condiciones, con humedad constante y filtraciones de las alcantarillas.." ${ }^{7}$

A continuación enumeramos los principales problemas de higiene y sanidad de la ciudad, enjuiciados por los autores del siglo pasado.

Manero señala en su obra que entre los graves inconvenientes que el puerto encierra, «el principal y más palpitante es el de contener el desagüe de todo el alcantarillado de la población, hasta el extremo de que muchos días se hace intransitable el paso por determinados sitios, a consecuencia de las metíficas emanaciones que de las aguas se desprenden."

No se olvida tampoco de exponer la situación de los dos hospitales de Alicante, el civil y el militar. En cuanto al civil, de-

6 Sánchez Santana, E.-Guardiola Picó, J.: Op. cit., pág. 73.

7 Sánchez Santana, E.-Guardiola Picó, J.: Op. cit., pág. 74. 
nominado Hospital de San Juan de Dios, y situado en el extremo de la ciudad, afirma que no reúne ninguna condición apropiada y su extensión es insuficiente para el número de enfermos que cobija. Respecto al Hospital Militar, llamado de San Fernando, señala que es lóbrego y está peor ventilado que el otro.

La casa de Beneficencia, cuyo objetivo es atender a los ancianos, huérfanos y niños abandonados es calificada de insalubre y falta de agua suficiente.

El estado de los cementerios también preocupa a nuestro autor porque el emplazamiento de la necrópolis en la parte noroeste de la ciudad no es el adecuado. Se muestra, además, enemigo de "la mala costumbre de hacer entierros pomposos, en las horas que más transitan las gentes, paseando el cadáver con gran séquito por las calles, hasta llevarlo a la Iglesia, donde se celebran sus exequias a presencia del difunto."

Por otro lado entre el cementerio y el cerro denominado Tosal, en un pequeño barranco, se abandonan los despojos de los animales muertos que sirven de pasto a los perros y a las aves de rapiña. Seguidamente propone que sea obligatorio enterrar a las bestias muertas. Una parte de la ciudad Ilama poderosamente la atención de Manero; se trata del Arrabal Roig, donde las frecuentes aguas estancadas lo han hecho foco permanente de paludismo. ${ }^{8}$

Primitivo Carreras, por su parte, escribe en 1886 que las causas que contribuyen al exceso de mortalidad ordinaria son: el absoluto abandono de las reglas higiénicas y sanitarias; la proximidad del cementerio; las malas condiciones de los edificios en que viven amontonadas las clases proletarias; la insuficiencia y mala calidad de los alimentos frecuentemente adulterados, el abuso del vino y de las bebidas alcohólicas así como los excesivos placeres sensuales. A continuación transcribe un trozo del discurso pronunciado por el exministro Sr. González en la exposición de su proyecto de ley de Sanidad, presentado a las Cortes el 20 de marzo de 1882. Dice así: "En la actualidad, los servicios municipales están casi abandonados; la reglas de hi-

8 Manero, E.: Op. cit., págs. 60 y ss. 
giene en desuso, aun en los establecimientos públicos... - también considera abandonada - ...la asistencia a los enfermos pobres, la vacunación, la limpieza de las calles y plazas..., el desagüe de los terrenos pantanosos, la higiene minera, la estadística demográfica y el estudio de la topografía médica."

Observamos, pues, que el problema era nacional. Y nuestro autor no comprende que servicios tan importantes como los anteriormente mencionados, estén entregados, sin fiscalización, a la buena voluntad de los alcaldes. Por último se queja amargamente de que no haya control sobre los enfermos ni esté establecida la desinfección obligatoria en los lugares donde se produzca una enfermedad contagiosa. ${ }^{9}$

En 1894 los problemas son los mismos y los redactores del Informe de la Junta Municipal de Sanidad de ese año señalan que es necesario dragar el puerto por la cantidad de inmundicias que contiene. Además proponen llevar las alcantarillas un kilómetro, por lo menos, mar adentro, por medio de grandes tubos de fundición.

La zona comprendida en la parte este de la playa, entre el muelle y la Albufereta, la consideran como zona palúdica.

Por último urgen la traída de aguas potables abundantes para satisfacer las necesidades de la población. ${ }^{10}$ Este problema se empezaría a solucionar afortunadamente en 1898, pero el siglo XIX concluía en esas fechas.

Los autores de la Memoria Higiénica de Alicante sostienen que el problema del agua es fundamental y grave ya que ubebemos sólo el agua indispensable y, en muchos casos, porque llega turbia o bien se altera en los depósitos..., ni aun la precisa para apagar la sed. Y aun para esto, hay que pagarla, por lo que la mayor parte de la población, esa gran masa social que constituye la clase proletaria, hace uso de unas aguas que no son potables, y a una alimentación malsana, agrega un agua de mala calidad".

Otro problema que subrayan es el del cementerio que ahora resulta que está practicamente en la ciudad, ya que han pasado

9 Carreras, P.: Op. cit., págs. 57, 65 y 66 .

10 Gadea y Fernández, E.: Junta Provincial de Sanidad, págs. 7 y 8. 
once años desde las observaciones que hizo Manero respecto al mismo. El estado de las instituciones hospitalarias no varió, hasta el punto que nuestros autores se niegan a llamar hospital a un lugar donde no existe patio para pasear los convalecientes, ni cámara de desinfección; ni sitio, puesto que los enfermos podían ver desde la cama lo que pasaba durante una autopsia. Los niños están mezclados con los adultos y no existe el aislamiento necesario para las enfermedades infecciosas.

En lo que respecta al Hospital Militar constatan que su estado es, sencillamente, ruinoso. También se refieren al estado de la Casa de Socorro y de la Beneficiencia Domiciliaria. Hay que decir que esta institución sanitaria se inauguró el 2 de noviembre de 1883 y se estableció en la planta baja del Ayuntamiento, precisamente en lo que hoy es el Archivo Municipal. Su personal era el mismo que el de la Beneficencia Domiciliaria y constaba de seis médicos y dos practicantes. Pero la asistencia domiciliaria tenía el problema de la irregularidad del servicio upor no estar hecho el padrón de pobres. Se trató de hacerlo, pero se encontraron con que el número de pobres era tan exhorbitante, que aun en épocas normales, no hubiera sido posible prestarles asistencia médica, ni aun duplicando el número del personal médico. En vista de esto, se ha adoptado la resolución de no prestar asistencia médica a ningún pobre que lo solicite, por más de una vez, si la enfermedad no es grave, hasta que el interesado haga una exposición al señor alcalde, y éste, previa información, decrete su inclusión en la lista de pobres con derecho a la asistencia médica».

Nuestros autores piden, en consecuencia, una mayor organización y el incremento del personal facultativo, aunque son conscientes de las implicaciones sociales que trae consigo la asistencia sanitaria y reconocen que "para dar salud al cuerpo, no bastan las más de las veces, los cuidados médicos; precisan también un régimen alimenticio adecuado y medio ambiente todo lo higiénico posible, y esto está todavía por hacer en este desventurado pueblo." ${ }^{11}$

Anteriormente hemos mencionado las implicaciones sociales que necesariamente tienen las cuestiones sanitarias. Por es-

11 Sánchez Santana, E.-Guardiola Picó, J.: Op. cit., págs. 56, 114, 117-119. 
ta razón vamos a exponer sucintamente las actividades productivas a las que debía su existencia la población, incidiendo especialmente en los barrios de Villavieja y Arrabal Roig.

A lo largo del siglo XVIII los pescadores se concentraban precisamente en los dos barrios mencionados. Los marineros, por su parte, habitaban el Arrabal de San Francisco.

Un informe de la Comisión inspectora de los establecimientos sanitarios fechado en septiembre de 1883 y dirigido al Cabildo municipal, señala que las dos terceras partes de la población perteneciente a la Parroquia de Santa María son gentes miserables, y su mayor número libra su existencia en la mendicidad." ${ }^{12}$

El acta capitular de 22 de diciembre de 1876 indica que los habitantes de Villavieja y Arrabal Roig son en su mayor parte marineros. ${ }^{13}$

Manero, en su obra publicada en 1883, afirma que el Arrabal Roig sirve de morada a los pescadores. ${ }^{14}$ Lo mismo se dice en el informe de la Junta Local de Sanidad, publicado en 1894. ${ }^{15}$

Entre los siglos XVIII y XIX no se dio un cambio socioprofesional en los barrios mencionados. Eran de los más pobres y el sector productivo predominante en ellos era el primario.

En lo que respecta a la ciudad propiamente dicha, esto es, sin las partidas rurales, el censo municipal de 1841 presenta porcentajes del 42,$6 ; 29,6$ y 27,7 para los sectores primario, secundario y terciario respectivamente. Si se contara con los datos de las partidas rurales el porcentaje del sector primario sería superior. ${ }^{16}$

Manero nos dice que «buena parte de los alicantinos se halla dedicada en el mar, bien al tráfico de la navegación, bien a la pesca; otros a las operaciones comerciales, y una gran porción

A. M. A. Libro de Actas 127.

A. M. A. Libro de Actas 168.

MANERO, E.: Op. cit., pág. 56.

GadeA Y PRO, J.-Fernández, E.: Op. cit., pág. 8.

GIMÉNEZ LóPEZ Y E.: "Alicante en el siglo XVIII. Economía de una ciudad portuaria en el antiguo régimen", pág. 186. 
de jóvenes al cultivo de la teneduría de libros por partida doble. La mujer de la ciudad tiene ocupación, cuando su pobreza lo exige, en la Fábrica Nacional de Tabacos. De las 5.000 operarias que el establecimiento sostiene, más de 3.000 pertenecen a la capital, las otras concurren todos los días que hay trabajo desde otros pueblos o lugares más o menos distantes".

Dentro de la llamada clase jornalera distingue dos clases de trabajadores: los jornaleros del campo y los jornaleros de oficio o artesanos. Las horas de trabajo para ambos son idénticas; desde las seis de la mañana hasta las ocho, descansan una hora, que emplean almorzando; trabajan luego tres horas más, a las doce comen, y a la una $o$ a las dos, según sea invierno o verano respectivamente, vuelven al trabajo, que termina al anochecer. Más adelante añade:

Poca gente ocupa Alicante en los campos, y esto es, sin du$\mathrm{da}$, efecto del insuficiente producto que las tierras dan, necesariamente por la escasez de aguas. Los años de sequía son una desgracia casi perenne en este suelo, que sólo necesita dos riegos buenos cada año, para asegurar las cosechas; $y$, con todo, como se pasan períodos tan larguísimos sin llover, el labrador recurre al doloroso trance de la emigración, abandonando patria e hijos en busca del sustento que suele encontrar en las colonias francesas de Africa. El jornalero del campo percibe muy corto salario... y, necesariamente, ha de reducir su alimentación al consumo de vegetales y algún poco de salazones... Los oficios ocupan una gran parte de gente; las operaciones de carga y descarga de buques y el servicio de almacenes, también sostienen muchas familias". ${ }^{17}$

Las pinceladas sociológicas anteriormente expuestas com. pletan lo quie no ha querido ser más que una aproximación a la realidad de dos barrios alicantinos en el siglo XIX; inscribiéndolos en el marco de la totalidad del término municipal.

Una vez reseñada la realidad higiénico-sanitaria, urbana y social, vamos a pasar al tema de fondo de este artículo. Se trata de averiguar cuál era la causa de las defunciones en una población perfectamente localizada dentro del término municipal. Señalaremos asimismo las enfermedades más destacadas y los

Manero, E.: Op. cit., págs. 124, 129 y 130. 
problemas a la hora de realizar una valoración objetiva de los datos obtenidos.

Los conocimientos médicos en cuanto al diagnóstico y tratamiento de las enfermedades dejan mucho que desear, como hemos podido comprobar al consultar los datos ofrecidos por los libros parroquiales de defunciones. No es necesario recordar que los principales avances de la medicina y la biología se produjeron a finales del siglo XIX. Se desconocían, por lo tanto, los verdaderos agentes causantes de muchas enfermedades $y$, lo que sólo era un síntoma de una determinada dolencia se convertía, en el sujeto causante de la enfermedad.

Los datos que poseemos sobre la causa de las defunciones se ciñen a los años comprendidos entre 1840 y 1900.

El mayor porcentaje de mortalidad lo produce la llamada «inflamación», con el 11,5\% del total de defunciones computadas. En este caso no se puede hablar de diagnóstico puesto que no sabemos exactamente cuál era la verdadera causa de la expresada "enfermedad". Sabemos que, muchas veces, se trata de inflamaciones del vientre puesto que se menciona explícitamente, pero en otras ocasiones no se especifica nada. La mayoría de los afectados son párvulos, pero se da en todas las edades. A partir de 1880 disminuye considerablemente el número de defunciones por esta causa. Pensamos que la razón es la mayor precisión en la calificación de las enfermedades. Evaristo Manero señala en su obra que: "las enfermedades agudas adquieren en este país (Alicante) muy a menudo un aspecto grave y alarmente..., las inflamaciones de carácter agudo han de ofrecer más vehemente exasperación en este punto que en cualquier otro del interior de la península». ${ }^{18}$

A continuación, la pulmonía es la que más víctimas mortales produce con el 9,5\% del total. Le sigue el cólera con el 8,9\%; pero, a diferencia de la anterior, no presenta una regularidad sino que se centra en los años: 1854, 1865 y 1885.

La llamada "dentición" arrancaba muchas vidas entre los niños y representa el $6,7 \%$ de las defunciones. Las palabras del

Manero, E.: Op. cit., págs. 476-477. 
conocido médico decimonónico mencionado son suficientemente expresivas: "los niños, en el periodo de la dentición, pagan un caro tributo..., hay que consignar sin reserva que en los niños de la clase pobre el pronóstico es muchísimo más grave que en los de la clase acomodada". ${ }^{19}$

Las gastritis, enteritis y gastroenteritis representan el $4,5 \%$ de las defunciones. No obstante hay que pensar que el número porcentual debería ser bastante mayor, puesto que sólo constan con regularidad a partir de 1875 . Es posible que, con anterioridad, se confundiese con la inflamación o la dentición. Lo que sí está claro es que "siendo considerablemente mayor el número de enfermos de los órganos digestivos en esta localidad, la cifra de los fallecimientos que a las enfermedades de ellos corresponde, está por debajo de la que dan los que padecen del pecho, que son también casi la mitad menos que los otros". ${ }^{20}$ Las causas de la mortalidad debida a trastornos digestivos es atribuida a la mala e inadecuada alimentación de los niños y de los mayores.

La difteria, con el $4,3 \%$, representa un porcentaje muy elevado, si tenemos en cuenta que aparece como tal a partir de 1860. Desde 1880 ocupa los lugares más altos en cuanto a número de fallecidos. Durante el quinquenio 1880-1884 fue la principal causante de las defunciones totales.

La tuberculosis pulmonar, con el 4,2\%, presenta una cierta regularidad en todo el período estudiado aunque aumenta claramente a partir de 1880. Manero señala que la enfermedad es superior en la mujer que en el hombre debido, según él, a que la ocupación de las cigarreras en la fábrica de tabacos produce muchas tísicas, ya que trabajan "en insalubres cuadras". A esto añade la mala calidad de los alimentos que adquieren en la venta pública. Durante el sexenio 1895-1900 la tuberculosis fue la tercera causa de las defunciones.

La viruela ocupa el octavo lugar en la serie de enfermedades causantes de mayor mortalidad. Su porcentaje es del $4 \%$, y se presenta a lo tarao de todo el período con las excepciones del

19 lbid., pág. 481.

20 lbíd., pág. 483. 
quinquenio que va de 1850 a 1854 . En el período 1885-1889 fue la principal causa de los óbitos. Sin embargo hay que tener en cuenta que en 1887 la viruela tenía carácter de epidemia con 62 muertos en el término parroquial de Santa María, y diez años más tarde, en 1897, fallecieron 38 personas por esta misma causa. Respecto a la vacunación, Manero señala que la clase proletaria la menosprecia, aunque las corporaciones municipales "van facilitando de algunos años a esta parte - (1880) - tubos de vacuna al cuerpo de médicos titulares, para que procedan a inocular gratuitamente a las gentes pobres". Sin embargo, añade, refiriéndose a las madres que piensan vacunar a sus hijos, que éstas "lejos de concurrir al consultorio del médico, donde encontrarían una acertada inoculación, acuden a la casa del barberon. ${ }^{21}$

La apoplejía, con el 3,8\%, es frecuente causa de defunción en los adultos. Las meningitis y ataques cerebrales, con el $3,3 \%$ del total de óbitos son padecidas en su inmensa mayoría por párvulos.

La "eclampsía», con el 3,2\%, es la siguiente dolencia, por Ilamarla así, desencadenante de las defunciones. Ataca a los niños en la inmensa mayoría de casos, aunque es enfermedad propia de mujeres. Por esta razón no se puede considerar a este término como un verdadero diagnóstico sino que, como ya reconoció Manero: "la inmensa mayoría de las veces es sintomática de otros padecimientos". Y más adelante añade: "el proceso de eclampsía casi siempre ocurre en aquellos tiernos seres al agravarse los síntomas intestinales, inflamatorios o catarrales que constituyen el padecimiento principal». ${ }^{22}$

Hemos de señalar, además, que el término eclampsía aparece con mayor frecuencia a partir de 1880, al igual que la difteria y la bronquitis; mientras que términos como el de "dentición» e "inflamación» descienden vertiginosamente a partir de esta misma fecha.

El Ilamado «espasmo» constituye el 3,2\% del total de óbi-

Ibid., págs. 186 y 491. 
tos. También baja ostensiblemente a partir de 1880 y afecta fundamentalmente a los párvulos.

El sarampión produjo, en el área del término parroquial, el $3,1 \%$ de las muertes. Si bien no tuvo la letalidad de la viruela, no por ello dejaron de haber años en que adquirió la categoría de brote epidémico como en 1840,1844 y 1849 con 18, 19 y 16 defunciones respectivamente. $Y$ ya más tarde, en 1886, con 25 párvulos fallecidos. Manero se queja de que "la mayor parte de los invadidos, o eran tratados por sus mismas madres, o por la inmensa cohorte de barberos e intrusos que aqui pululan atrevida y descaradamente, prostituyendo, con vergonzoso sarcasmo, el sagrado sacerdocio de la medicinan. ${ }^{23}$

Las Ilamadas "calenturas", representan el 3\% del total de óbitos. En este caso nos encontramos en el mismo caso que en otras enfermedades, ya que no sabemos qué significa exactamente el término empleado. En el quinquenio que va de 1850 a 1854 hay gran cantidad de párvulos en los que no consta la causa de su defunción. A partir de 1880 esto no sucede.

El paludismo, con el 2,6\% de los óbitos, presenta diversas oscilaciones a lo largo del período estudiado. En el término parroquial estudiado en el presente trabajo, el paludismo se dejó sentir en años como: 1840 y 1841 con 17 y 11 defunciones; pero, sobre todo, en los años: 1884, 1885, 1886 y 1887 con: 12, 13, 25 y 14 fallecimientos. En contraposición a esto, durante el periodo comprendido entre 1845 y 1864, sólo se registran dos casos. Pero hay que tener en cuenta que algunas de las llamadas "calenturas" podían ser palúdicas y que, por otro lado, no conocemos la letalidad de los diferentes brotes de paludismo. En otras palabras, el hecho de que no muriera mucha gente de paludismo no quiere decir que no hubiera. Aparte de los datos numéricos, encontramos múltiples referencias al paludismo en las actas capitulares de comienzos del siglo XIX. Ya el 25 de mayo de 1805, un grupo de comerciantes elevaron un escrito a S.M. en el que pedían la desecación de las lagunas del Porquet, distantes un cuarto de legua de la ciudad, y que tenían esparto puesto a fermentar; al que consideraban causante del mantenimiento de unas fiebres tercianas que se padecían. ${ }^{24}$

23 Ibid., pág. 199.

24 A. M. A. Arm. 1 Libro 79. 
Por otro lado, sabemos que, en el siglo pasado, también hubo frecuentes brotes de paludismo. Así Cavanilles en su obra señala que "la Albufereta es un depósito natural de aguas estancadas $-y-$ las aguas de esta laguna... producen tercianas, muchas veces rebeldes y malignas" ${ }^{25}$ Townsend, por su parte en sus viajes de 1786 y 1787, Ilegó a la conclusión de que ula enfermedad más corriente en esta parte de España es la fiebre intermitentem. ${ }^{26}$

Manero señala las zonas de mayor frecuencia de la enfermedad y afirma que "en el Arrabal Roig, parece que desde tiempo inmemorial se vienen padeciendo esas calenturas, tal vez por la proximidad de un pequeño barranco que suele contener baches de aguas cenagosas... y en los cuales las mujeres de aquel barrio lavan sus ropas". ${ }^{27}$ Conviene recordar también las frecuentes comunicaciones al Ayuntamiento señalando la existencia de fiebres intermitentes en uno y otro punto de las partidas rurales.

Las cardiopatías aparecen con el nombre de lesiones orgánicas del corazón. A partir de 1880 representan una cifra elevada respecto al total de defunciones, y en el sexenio 1895-1900, ocupan el segundo lugar en mortalidad. Para todo el período estudiado su cifra porcentual es de $2,6 \%$.

Las bronquitis aumentan constantemente a partir de $1880 \mathrm{y}$ suponen un porcentaje del 2,3\%; ligeramente superior a las enfermedades catarrales y del pecho, que suponen el $2,1 \%$. Es curioso constatar la existencia de la muerte por "vejez", que representa el 1,6\% del total. Las Ilamadas "ansias" afectan al 1,4\% de los fallecidos. El asma, por su parte, causó el 1,1\% de las defunciones. El raquitismo y la entero-colitis muestran cifras porcentuales del $1 \%$, al igual que el cáncer. De éste último podemos afirmar que el $75 \%$ de los fallecidos son mujeres y la región afectada es la matriz.

CAVANILles, A. J.: "Observaciones sobre la historia natural, geografía, agricultura, población y frutos del Reino de Valencia", pág. 248.

Garcia MERcadal: "Viajes de extranjeros por España", vol. III, José Townsend, Viaje a España hecho en 1786-1787, pág. 1.622.

Manero, E.: Op. cit., págs. 208 y 73. 
Las muertes por sobreparto son dignas de reseñar, con el $0,9 \%$ del total. A partir de 1880 disminuyen considerablemente, produciéndose desde esta fecha hasta 1900, ocho defunciones; mientras que entre 1840 y 1880 se producen 55 fallecimientos. En este sentido Manero señalaba en su obra: "Doloroso es que la mujer no se despeje de ese mal entendido rubor en el importante acto de la parturición, que la conduce a la rutinaria asistencia de personas de su sexo, para ponerse en manos de comadrones entendidos, los que, seguramente, le evitarían una buena parte de molestias". 28

La fiebre amarilla, con el 0,8\%, ocupa el siguiente puesto como consecuencia de la epidemia de 1870 , que produjo 60 defunciones en el término parroquial de Santa María. Por lo demás, nada se puede decir puesto que la epidemia se ciñó al año mencionado, no repitiéndose nuevamente. El tifus alcanza una cifra porcentual del $0,7 \%$ pero, al contrario que la fiebre amarilla. se mantiene constante a partir de 1870 y sin cifras elevadas en ninguno de los años estudiados. Las gangrenas suponen el $0,7 \%$ de los fallecidos y las hepatitis y reumas el $0,5 \%$ y $0,4 \%$ respectivamente. Los muertos por accidente, con un porcentaje del $0,4 \%$, son los más bajos, aunque, por supuesto, no se trata de ninguna enfermedad.

Debido a las insuficiencias observadas en los términos empleados para definir las distintas enfermedades, seria conveniente realizar un análisis de la frecuencia de las distintas dolencias a partir de 1880 . Hemos elegido esta fecha porque consideramos que a partir de ella se da una mayor claridad en la calificación de las enfermedades.

Así comprobamos que el mayor porcentaje de defunciones $(9,6 \%$ es causado por la neumonía, seguida de la gastroenteritis $(8,8 \%)$. A continuación viene la difteria $(8,6 \%)$ y la eclampsía $(8 \%)$. La tuberculosis presenta el $6,5 \%$, seguida por las lesiones del corazón $(5,7 \%)$ y las bronquitis $(5,6 \%)$. La viruela se coloca en octava posición $(5,2 \%)$, seguida por la apoplejía $(5,1 \%)$. El paludismo representa el 3,8\% y las meningitis el 3,4\%. A continuación aparecen las enfermedades catarrales y del pecho

28 Ibid. pág. 189. 
$(3,3 \%)$; la dentición $(3 \%)$ al igual que las inflamaciones del vientre; el raquitismo (2,5\%); el sarampión $(2,2 \%)$; el asma $(1,9 \%)$. Es curioso observar cómo la "inflamación" que para el período 1840-1900, era la causante del mayor número de defunciones, ahora sólo representa el 1,6\%; lo cual nos hace pensar que este término se aplicaba, en muchos casos, para encubrir la ignorancia sobre la verdadera causa de la defunción. El cáncer afecta al $1,5 \%$ y, como ya dijimos anteriormente, en sus tres cuartas partes, son mujeres las que lo contraen. La entero-colitis, unida a la disentería, representa el 1,3\% del total de defunciones. Las hepatitis, el tifus y el cólera presentan un porcentaje del $1,2 \%$ respectivamente. Por último, los fallecidos por vejez y por calentura muestran las cifras porcentuales más pequeñas, con el $0,9 \%$ y $0,8 \%$ respectivamente. Las restantes enfermedades suponen el $4,1 \%$ del total.

Esta nueva clasificación, aunque más restringida en cuanto al tiempo abarcado, ofrece mayor confianza que la anterior, aunque haya que poner, pese a todo, serias dudas respecto a algunos términos empleados.

En la "Memoria Higienica de Alicante», impresa en 1894, sus autores afirman que, en cuanto a mortalidad, sobresalen en primer lugar, las enfermedades infecciosas y contagiosas, seguidas de las del aparato respiratorio, digestivo, cerebro-espinal y circulatorio. ${ }^{29}$ Seguidamente se quejan de la enorme cantidad de niños arrebatados por la difteria, y en este sentido, exponen: "Hemos presenciado muchísimas veces alrededor de la camita de un enfermo agonizante de difteria, a muchas madres con sus hijos en brazos, para las que no ha sido suficiente la voz del médico para hacerlas salir de aquella atmósfera de muerte. Por ignorancia o por terquedad, no han abandonado al enfermo mientras no arrojó el último suspiro y aun entonces, han ayudado a la desconsolada madre del diftérico a cubrir de flores el cadáver de su tierno niño, y han consentido, sino han mandado a los suyos, que acompañaran a su amiguito hasta darle sepultura. Esto se ve todos los días en esta capital". ${ }^{30}$

29. Sánchez Santana, E.-Guardiola Picó, J.: Op. cit., pág. 23.

30 Ibíd., pág. 41. 
Respecto a la tuberculosis señalan: «aquí nadie piensa en aislar a ningún enfermo; ni aun en el mismo Hospital Provincial, existe un local independiente para esta clase de enfermos; de modo que ocupan al llegar, la primera cama vacanten. En cuanto a las reglas de desinfección afirman: "No se observa ninguna regla para la desinfección de ropa, muebles, ni habitaciones. Todo se hace lo mismo, las ropas al montón de la colada que si no, van directamente al lavadero empapadas con el vómito o las deyecciones del colérico, con la membrana diftérica o con la pus o las costras del varioloso; alli se mezclan con otras ropas y en la misma canasta que las llevaron al lavado, las colocan una vez lavadas y secas... En la habitación donde muere un varioloso, un diftérico o un tísico, ni siquiera se lava; a lo sumo y sólo en algunos casos, se coloca una cazuela con un puñado de azufre que se quema, y esta ridícula farsa sustituye a la verdadera desinfección."

Respecto a las enfermedades del aparato digestivo señalan la incidencia que en ellas tiene el problema del abastecimiento de aguas. No olvidemos que hasta 1898 Alicante no empezó a solucionar este problema y se abastecía de las aguas de los antiguos manantiales casi agotados y de las procedentes de la Alcoraya, aparte de las que podian conseguirse en San Vicente. Pero "como el agua que sirve para la bebida se paga, resulta que los pobres, que aquí como en todas partes, constituyen una gran parte de la población, hacen uso de las antiguas aguas de Alicante que no son potables, y alterando las funciones químicas de la digestión, dan lugar al desarrollo de gran número de dispepsias de todas clases". ${ }^{31}$

Por otro lado constatan que, desde que se instaló el Laboratorio Químico Municipal, a mediados de la década de los ochenta, más del $50 \%$ de las sustancias que se analizaron resultaron adulteradas.

En el libro titulado «Medios para mejorar las condiciones higiénicas de Alicante", impreso en 1886, su autor se lamenta de las nulas medidas de desinfección y control que se llevan a cabo con enfermedades como la viruela. Son interesantes sus obser-

31 Ibíd., págs. 43 y 44. 
vaciones puesto que precisamente en 1887 se produjo una epidemia variolosa, que se llevó 62 vidas en el término parroquial de Santa María. A su vez los autores de la "Memoria Higiénica de Alicante" señalan que en el quinquenio 1889-1893, de los 8.150 nacidos sólo fueron vacunados en la Casa de Socorro y en el Instituto 1.541, quedando demostrado, por consiguiente, que los barberos y los practicantes eran los encargados de la vacunación en la capital. ${ }^{32}$

Si para comprender la evolución de la población es importante señalar las crisis de subsistencias, los problemas del abastecimiento de aguas potables, los acontecimientos políticos y bélicos, las condiciones meteorológicas y tantos otros; también es fundamental, conocer el estado de avances médicos, las condiciones sanitarias, las principales enfermedades y el nivel de conciencia del vecindario respecto a los problemas de sanidad e higiene. En el presente trabajo y con las citas anteriores hemos querido reflejar, a veces de forma anecdótica, pero real, no sólo las principales enfermedades sino la mentalidad que tenía la mayoría de la población en lo referente a las cuestiones sanitarias y de higiene pública. 
BIBLIOGRAFIA

Carreras, P.: "Medios de mejorar las condiciones higiénicas de Alicante». Alicante, Antonio Reus, 1886.

CAVANILLES, A. J.: "Observaciones sobre la historia natural, geografía, agricultura, población y frutos del Reino de Valencian, vol. II. 1795, Ed. Facsímil.

Gadea y Pro, J.-Fernández, E.: "Junta Provincial de Sanidad. Informe de las memorias presentadas por las Juntas Municipales". El Graduador, Alicante, 1894.

Garcia Mercadal: "Viajes de extranjeros por España», vol. III: José Townsend, "Viaje a España hecho en 1786-1787». Madrid, 1962.

GIMÉnEZ LóPEZ, E.: "Alicante en el siglo XVIII. Economía de una cíudad portuaria en el antiguo régimen». Diputación Provincial de Valencia, Valencia, 1981.

MANero, E.: "Estudios sobre la topografía médica de Alicante». Carratalá y Gadea, Alicante, 1883.

Sánchez Santana, E.-Guardiola Picó, J.: “Memoria Higiénica de Alicante». Costa y Mira, Alicante, 1894. 